\title{
Early CRRT and antibiotic management in shock patient due to urosepsis with immunocompromised post renal transplantation
}

\author{
Prabowo $\mathbf{S}^{1}$, Dita $\mathrm{A}^{2}$ \\ ${ }^{1}$ Dr. Sandhi Prabowo, ${ }^{2}$ Dr. Dita Aditianingsih, both authors are attached with Department of Anesthesiology and \\ Intensive Care, Cipto Mangunkusumo General Hospital, Universitas Indonesia, Jakarta, Indonesia.
}

Corresponding Author: Dr. Sandhi Prabowo, Email: sarahsandhi@gmail.com

\begin{abstract}
Septic shock is a major cause of morbidity and mortality in the ICU. A 32-year-old patient was diagnosed with septic shock due to urosepsis, hospital-acquired pneumonia (HAP), and acute kidney injury (AKI) post renal transplantation. Continue Renal Replacement Therapy (CRRT) was performed to remove inflammation mediator. Broad-spectrum antibiotics, blood glucose control, adequate volume status, nutritional support, and temporary withdrawal of immunosuppressive drugs were ensured. Patient was stable on the $5^{\text {th }}$ day, extubated by day $8^{\text {th }}$, and discharged from ICU 10 days later. It can be concluded that early CRRT could prevent organ failure and further complications caused by septic shock.
\end{abstract}

Key words: Antibiotic management, CRRT, Renal transplantation, Septic shock, Urosepsis

\section{Introduction}

Seventy five percent of renal transplant recipients are infected in the first year of post renal transplantation because of the use of immunosuppressant and environmental interactions [1]. The infection is often caused by reactivation of recipient infections, especially urinary tract infections, tuberculosis, transmission of infection from donors, surgical wound infections, intravenous catheters and urine catheters. The risk of infection is predisposed by immunosuppressive agents.
Focal infection of the urinary tract can lead to bacteremia that will become a systemic infection (urosepsis). Incidence of urosepsis is $20-30 \%$ of all occurrences of septicemia and more often comes from complications of infection in the urinary tract (Table-1) [2]. Mortality reaches $20-49 \%$ when accompanied by shock. Proper treatment should be quick and adequate to prevent organ failure and further complications.

Table-1: Structural and functional abnormalities of the urinary tract associated with sepsis [2].

\begin{tabular}{|c|c|}
\hline Obstruction & $\begin{array}{c}\text { Congenital: urethral stricture, phimosis, urethrocele, polycystic kidney disease } \\
\text { Acquired: Calculi, prostatic hypertrophy, tumors of the urinary tract, trauma, } \\
\text { pregnancy, radiation therapy }\end{array}$ \\
\hline Instrumentation & $\begin{array}{c}\text { Indwelling urethral catheter, ureteric stent, nephrostomy tube, urological } \\
\text { procedures }\end{array}$ \\
\hline Impaired voiding & Neurogenic bladder, cystocele, vesicoureteral reflux \\
\hline Metabolic abnormalities & Nephrocalcinosis, diabetes, azotemia \\
\hline Immunodeficiency & Patients on immunosuppressive drugs, neutropenics. \\
\hline
\end{tabular}

The handling of urosepsis in post-transplant patients should be fast, adequate and balanced between immunosuppressive status and epidemiological exposure. In principle, the handling consists of handling of shock according to Survival Sepsis Campaign (SSC) bundle, broad-spectrum antimicrobial administration, including anti-fungal or antiviral if necessary, liquid and electrolyte management, Therapeutic Drug Monitoring (TDM) for immunosuppressant drugs and definitive

Manuscript received: $20^{\text {th }}$ February 2018

Reviewed: $28^{\text {th }}$ February 2018

Author Corrected: $7^{\text {th }}$ March 2018

Accepted for Publication: $13^{\text {th }}$ March 2018 


\section{Case Report}

action (urological causes). CRRT in the form of Continues Vena Venous Hemodiafiltration (CVVHDF) in High Volume Hemofiltration (HVHF) mode is one method that can be used as blood purification therapy to remove inflammation mediator.

\section{Case Report}

A 32-year-old man was admitted to the ICU with a major complaint of decreased of consciousness, shock and respiratory failure. He had historyof cystoscopy evaluation, cystography and replace nephrostomy renal allograft procedure a week before admitted. Previously, patient hadundergone renal transplantation 3 months ago. Diagnosis in ICU wereseptic shock due to urosepsis, hospital-acquired pneumonia (HAP) and chronic kidney disease (CKD) post renal transplantation.

The patient was given oxygen therapy with Non-Rebreathing Mask (NRM) of 10 liters per minute and fluid resuscitation with crystalloid (ringer lactate) $20 \mathrm{ml} / \mathrm{kgbw} / \mathrm{hour}$ without significant response. He was also given norepinephrine 0.5 $\mathrm{mcg} / \mathrm{kg} / \mathrm{min}$ to achieveMAP $>65 \mathrm{mmHg}$ (BP $104 / 70 \mathrm{mmHg}$ ), pulse was $125 / \mathrm{min}$ and $\mathrm{SpO} 2$ was $98 \%$. However, due to unstable hemodynamics, we decided to intubate and then performed Central Vena Catheter (CVC) cannulation.

Supportive laboratory results were as follows: hemoglobin $10.1 \mathrm{~g} / \mathrm{dL}$, leukocyte $27700 / \mathrm{mm}^{3}$, neutrophil segment $97.3 \%$, procalcitonin $(\mathrm{PCT}) 1079 \mathrm{ng} / \mathrm{mL}$, urea $55 \mathrm{mg} / \mathrm{dL}$, creatinine $3.8 \mathrm{mg} / \mathrm{dL}$, AST 67 units $/ \mathrm{L}$, ALT $59 \mathrm{units} / \mathrm{L}$, albumin $2.77 \mathrm{~g} / \mathrm{dL}$, blood gas analysis (BGA) artery pH $7.460 / \mathrm{pCO}_{2} 40.1 / \mathrm{pO} 2103.5 / \mathrm{BE} 5.2 / \mathrm{TCO}_{2} 28.8 / \mathrm{O}_{2}$ sat 97.6,BGA mixed vein pH $7.337 / \mathrm{pCO}_{2} 27.8 / \mathrm{pO}_{2} 58.4 / \mathrm{BE} 15 / \mathrm{TCO} 215 / \mathrm{O}_{2}$ sat 74.4 , lactate $7.2 \mathrm{mmol} / \mathrm{L}$ and electrolyte (sodium $134 \mathrm{mEq} / \mathrm{L}$, potassium $3.8 \mathrm{mEq} / \mathrm{L}$, chloride $95.4 \mathrm{mEQ} / \mathrm{L}$ ).Other laboratory examination results were within normal limits.

We have started CVVHDF dose $40 \mathrm{ml} / \mathrm{Kg}$ /hour with titration of norepinephrine, dobutamine, and vasopressin since day1. Also, antibiotics combination (meropenem $1 \mathrm{gr}$ t.i.d and levofloxacin $750 \mathrm{mg}$ q.d) and antifungal (micafungin $100 \mathrm{mg}$ q.d).

On day 4, the result of culture urine was E. coli and there was an increase of infection markers value (leukocyte 29700), so that the combination antibiotics was changed to tigecycline $100 \mathrm{mg}$ b.i.d and fosfomycin $2 \mathrm{gr}$ b.i.d.On day 5, Patient was stable. CVVHDF was stopped and then planned to do Slow Low Efficient Daily Dialysis (SLEDD). Vasopressin and dobutaminewas stopped. The day after, the patient started to wean from ventilator.

On day 7, Norepinephrine was tapered down until itwas stopped (MAP 70-90 mmHg). The infection markers (leukocyte 20820) was decreased, lactate was 1.8 and no fever. SLEDD was started on day 8 with UF 1000/4 hours and the patient was extubated 7 hours after that. Chest x-ray was done post extubation and showed decreased of infiltrates, pulmonary edema was reduced. Fosfomycin antibiotic (day 5) was replaced by imipenem cilastatin 1 gr t.i.d (based on sputum culture resistance).

Table-2: Description of CVVHDF Implementation in Patient.

\begin{tabular}{|c|c|c|c|c|c|c|c|}
\hline $\begin{array}{c}\text { CVVHDF } \\
\text { (hours) }\end{array}$ & $\begin{array}{c}\text { Replacement } \\
(\mathrm{ml})\end{array}$ & $\begin{array}{c}\text { Fluid } \\
\text { Removal } \\
(\mathrm{ml} / \mathrm{hour})\end{array}$ & $\begin{array}{c}\text { Heparin } \\
\text { rate }\end{array}$ & Dialysate & $\begin{array}{c}\text { Urea/ } \\
\text { creatinine }\end{array}$ & $\begin{array}{c}\text { Prod urine } \\
\text { (ml/kgbw/ } \\
\text { hours })\end{array}$ & $\begin{array}{c}\text { Daily balance / } \\
\text { Cumulative } \\
\text { balance (ml) }\end{array}$ \\
\hline 24 & $1000-500$ & $20-50$ & 0 & 1000 & $66 / 4.3$ & 0.04 & $273.3 /+1217.8$ \\
\hline 48 & $1000-200$ & 100 & 0 & 1000 & $96.6 / 2.09$ & 0.03 & $1225 /+2443$ \\
\hline 72 & $500-800$ & 100 & 0 & 1000 & $72 / 3$ & 0.05 & $145.8 /+2589$ \\
\hline 96 & 200 & 100 & 0 & 1000 & $138 / 37$ & 0.98 & $-27.2 /+2562.4$ \\
\hline
\end{tabular}

SLEDD (UF 1000-1500/ 4 hours) was done two cycles and then continued with Intermittent Hemodialysis (IHD) on day 12. On day 13, Infection markers showed better (leukocyte 16160, PCT 5.65 with no fever), so that the tygecyclin was stopped and replaced with bactrim forte (sulfamethoxazole and trimethoprim) per oraltwice a day. Imipenem and micafungin were stopped on day 15. The patient moved to the ward on the 18th day after second IHD in ICU (Daily balance $-374 \mathrm{ml}$ and cumulativebalance $-1544 \mathrm{ml}$ with urine output $2 \mathrm{ml} / \mathrm{KgBW} / \mathrm{hour}$ ). 


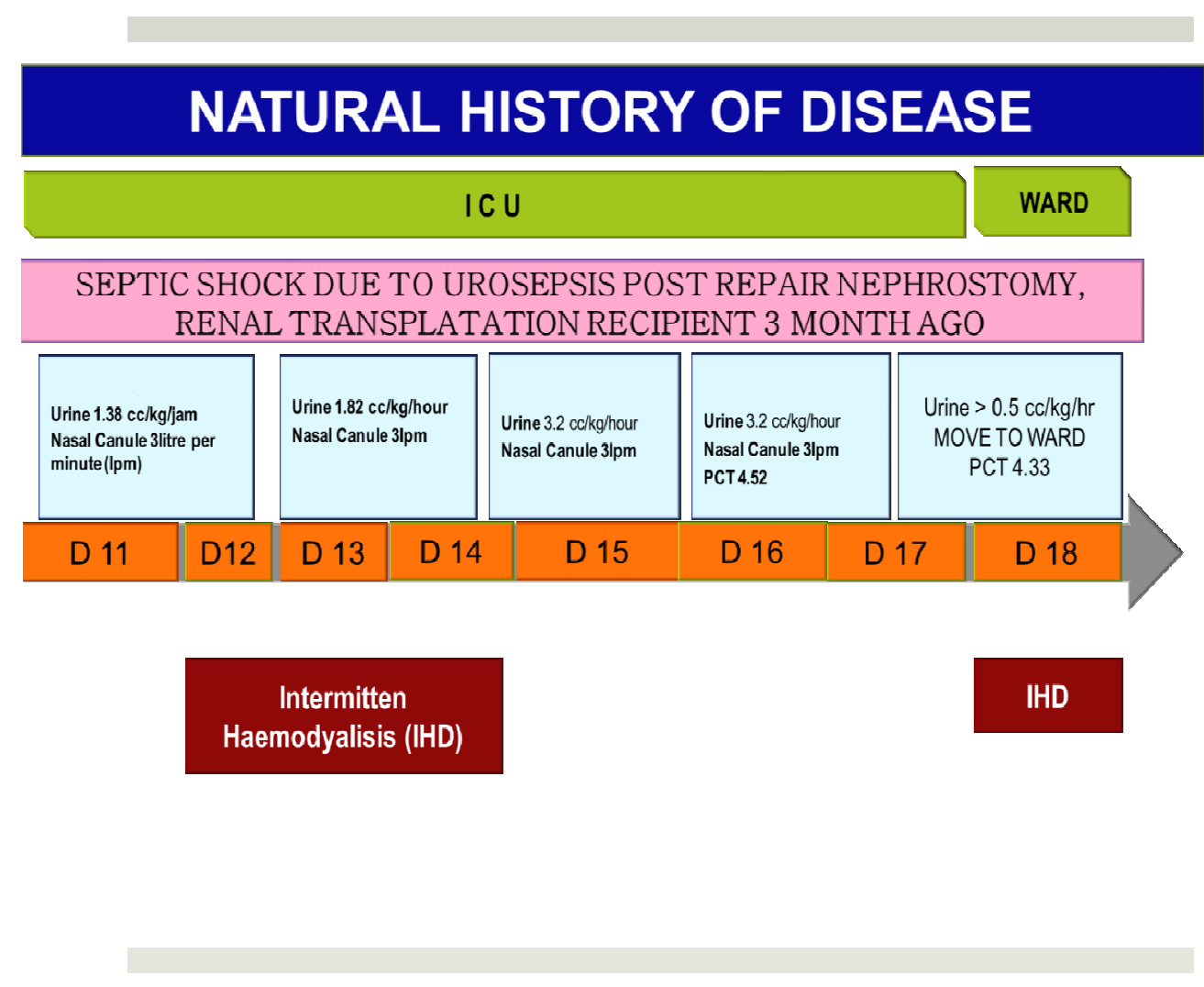

Figure-1: Natural history of disease

\section{Discussion}

At the time of ICU admission, the patient showed signs of sepsis shock. The diagnosis of septic shock was predicted by the rapid total score change in the Sequential Organ Failure Assessment (SOFA), with a score greater than 2 points. [3], [4] The patient was with hypotension and requiring vasopressors to maintain an average arterial pressure of $65 \mathrm{~mm} \mathrm{Hg}$ or higher and lactate serum greater than $2 \mathrm{mmol} / \mathrm{L}(18 \mathrm{mg} / \mathrm{dL})$ despite adequate volume resuscitation.

The risk factor for septic shock in this patientwas thought to be immunocompromised due to immunosuppressive drug consumption of cellcept, prograf, and methyl prednisolone. Inflammatory responses become dull due to immunosuppressant administration, making identification of infections in renal transplant recipients difficult. Although a source of infection is identified, a balance between transplant rejection and immunosuppressant modification remains to be maintained. Therefore a complete and comprehensive investigation is required to establish a diagnosis of UTI in post renal transplantation patients. In our patients, immunosuppressive drugs were suspended but tacrolimus was only reduced to $2 \mathrm{mg}$ b.i.d. Therapeutic Drug Monitoring (TDM) of tacrolimus was done so that the optimal dose $(5.0-20 \mathrm{ng} / \mathrm{ml})$ could be maintained in the plasma. In the first month of renal transplantation, the infection is often caused by reactivation of recipient infections, especially urinary tract infections, tuberculosis, transmission of infection from donors, surgical wound infections, intravenous catheters and urine catheters. In the first to six months, infection is often caused by viruses such as herpes, bacteria and fungi. Giessing (2012) found that majority incidence of the infection post renal transplantation etiology was viral infection [1].

The patient is currently undergoing a third month post-kidney transplant, developing an infection to septic shock. The result of urine culture was isolate E.coli. This is in accordance with previous research which mentions that the cause of bacterial infections after renal transplantation is similar to the primary infection-causing bacteria in the urinary tract of gram-negative coliform germs such as Escherichia coli (50\%), Proteus spp (15\%), Klebsiella enterobacter (15\%) and Pseudomonas aeruginosa (5\%). Gram-positive bacteria are also involved but the frequency is smaller, which is around 15\%. In the study of the European Study Group on Nosocomial Infections (ESGNI-004 study), by comparing patients using catheters and non-catheters, it is found that E.coli was 30.6\% in patients with catheters and $40.5 \%$ in non-catheters, Candida spp $12.9 \%$ in patients with catheters and $6.6 \%$ in non-catheters, P.aeruginosa $8.2 \%$ in patients with catheters and $4.1 \%$ in non-catheters.[5]. 


\section{Case Report}

Management in handling urosepsis in these patients in accordance with the principle of urosepsis in post renal transplant patients. After these patients are diagnosed with septic shock, sepsis bundles were performed. The vasopressor administration was started with norepinephrine to achieve MAP $>65 \mathrm{mmHg}$. Because the norepinephrine dose was too high (reaching $1.1 \mathrm{mcg} / \mathrm{kg} / \mathrm{min}$ ), the combination with vasopressin was administered. The inotropic administration was also performed due to high lactate and suspected SIMD (Sepsis-Induced Myocardial Dysfunction). The monitoring during resuscitation and therapy used parameters $\mathrm{ScvO} 2$ and lactate blood as a parameter of successful resuscitation and therapy in microcirculation level in addition to macro parameters such as blood pressure, CVP, and urine production that we had been using. Previously the balance of delivery and oxygen consumption was maintained by intubation so that oxygen consumption can be reduced as much as possible.

Resuscitation of fluids $(20 \mathrm{cc} / \mathrm{kgBW})$, electrolytes and acid-base are to restore the state to normal [3]. If there is electrolyte disturbance, it should also be corrected. When $\mathrm{K}$ serum is $7 \mathrm{meq} / \mathrm{L}$ or more, Renal Replacement Therapy (RRT) needs to be done. RRT is also required when serum creatinine is $>10 \mathrm{mg} \%$, BUN $>100 \mathrm{mg} \%$, or there is pulmonary edema, or even with patients with hemodynamic instability caused by cytokine storm. Continuous Renal Replacement Therapy (CRRT) can be a choice of modalities in patients with unstable hemodynamics [6]. CRRT modes that can be used vary according to patient needs. CRRT in the form of Continues Vena Venous Hemodiafiltration (CVVHDF) in High Volume Hemofiltration (HVHF) mode is one method that can be used as blood purification therapy, in addition as renal replacement therapy in patients with catecholamine-resistant sepsis shock.

During the first 6 hours of treatment in the ICU, the patient's condition decreases and urine does not come out. The patient is suspected of having a cytokine storm (ur/cr $55 / 3.8 \mathrm{mg} / \mathrm{dL}$, lactate $7.2 \mathrm{mmol} / \mathrm{Land}$ procalcitonin $1070 \mathrm{ng} / \mathrm{mL}$ ) and it was decided to initiate CVVHDF with a dose of effluent rate of $40 \mathrm{ml} / \mathrm{kg} / \mathrm{h}$ (blood flow rate $80-10 \mathrm{ml} / \mathrm{hour}$, fluid removal $60 \mathrm{ml} / \mathrm{h}, 1000 \mathrm{ml} /$ hour replacement, $1000 \mathrm{ml} /$ hour dialysate, heparin rate of $2 \mathrm{ml} /$ hour). CVVHDF was performed for 5 days non-stop, then after urine started to come out (Table 2), CVVHDF was carried out with SLEDD as needed. After CVVHDF, the patient's condition has stabilized, MAP $\geq 65 \mathrm{mmHg}$ with only norepinephrine, infection marker improved and the patient was extubated (Figure 2).

The broad spectrum antibiotic administration of meropenem and levofloxacin was immediately given within the first hour of patient admission to the ICU. The micafungin antifungal was also administered considering the patient was immunocompromised with a candida score 3. A culture resistance examination was taken to find the source of the infection and determine the definitive antibiotic. This is consistent with Naber study mentioning that administration of fluoroquinolone and piperacillin/tazobactam injectable antibiotics was recommended for urosepsis therapy[7]. Bjerklund Johansen TE et al. in The Board of the European Society of Infections in Urology recommends the use of fluoroquinolone or aminoglycosides, combined with broad-spectrum cephalosporin or penicillins, or carbapenem groups for the management of urosepsis.

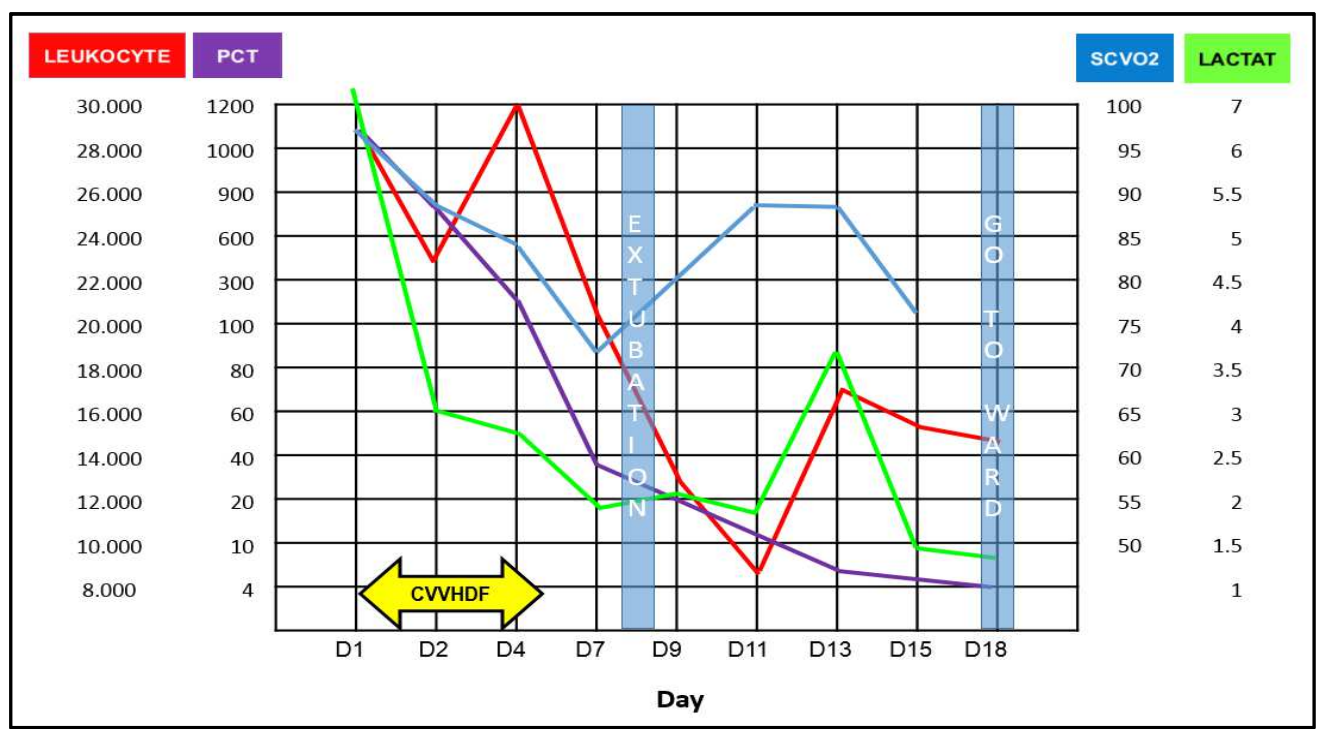

Figure-2: Marker of Infection during treatment at ICU 


\section{Case Report}

Administering antibiotics should be fast and effective so that the antibiotics given are broad-spectrum and includes all the germs that often cause urosepsis is a group of aminoglycosides (gentamicin, tobramycin or amikacin) group of ampicillin combined with clavulanic acid or sulbactam, $3^{\text {rd }}$ generation cephalosporin or fluoroquinolone group. Third generation cephalosporins are recommended to be given 2 grams at 6-8 hours intervals, for cefoperazone and ceftriaxone groups at 12-hour intervals. [2] Subsequent research by Concia and Azzini on levofloxacin proves that levofloxacin as an adjunctive therapy has an effect on renal excretion and is available in the form of intravenous and oral injections. [8]

In day 4 of treatment, E.coli is found in urine culture. The definitive combination of antibiotics according to the results of the culture of resistance is given to the patient were tigecycline $100 \mathrm{mg}$ b.i.d and fosfomycin $2 \mathrm{gr}$ b.i.d. The doses administered were normal doses and no dose adjustments were given as the patient was undergoing CRRT. Inotropic dose and vasopressor were reduced each day until they successfully stopped on the $7^{\text {th }}$ day. On the $8^{\text {th }}$ day the sputum culture result came out with Staphylococcus epidermidis bacteria.

This result was confirmed by pulmonary x-ray result indicating an infiltrate in the right lung. Based on the result of resistance, it was decided to replace fosfomycin with imipenem-cilastatin $1 \mathrm{gr}$ t.i.d $\left(\mathrm{D}_{1}\right)$. Patients were extubated on day 8 , hemodynamically stable. On day 12 , tigecycline $\left(\mathrm{D}_{9}\right)$ was stopped and replaced with Bactrim Forte. On day 15 , Imipenem $\left(D_{5}\right)$ and Micafungin $\left(D_{12}\right)$ were stopped. Marker infection before patient moved to the ward was leukocyte 14540 , PCT 4.33 , lactate 1.3 with urine output $2 \mathrm{cc} / \mathrm{kgBW} /$ hour.

\section{Conclusion}

The balance of Immunosuppressant and epidemiological exposure is important in the management of infections in post-transplant patients. A sharp diagnosis, early blood purification therapy, and good antibiotic management determine the success of therapy in these patients.

Management of such patients should use the most updated Survival Sepsis Campaign (SSC) guidelines adapted to the situation and conditions in the hospital where the patients are treated.

Funding: Nil, Conflict of interest: None

Permission of IRB: Yes

\section{References}

1. Giessing M. Urinary Tract Infection in Renal Transplantation. Arab Journal of Urology 2012;10(2): 162-8.

2. Bjerklund Johansen TE, Cek M, Naber K, Stratchounski L, Svendsen MV, Tenke P; PEP and PEAP study investigators; European Society of Infections in Urology. Prevalence of hospital-acquired urinary tract infections in urology departments. Eur Urol. 2007 Apr; 51 (4):1100-11; discussion 1112. Epub 2006 Aug 28.

3. Singer M, Deutschman CS, Seymour CW, ShankarHari M, Annane D, Bauer M, Bellomo R, Bernard GR, Chiche JD, Coopersmith CM, Hotchkiss RS, Levy MM, Marshall JC, Martin GSOpal SM, Rubenfeld GD, van der Poll T, Vincent JL, Angus DC. The Third
International Consensus Definitions for Sepsis and Septic Shock (Sepsis-3). JAMA. 2016 Feb 23;315(8): 801-10. doi: 10.1001/jama.2016.0287.

4. Bouza E, San Juan R, Muñoz P, Voss A, Kluytmans $\mathrm{J}$; Co-operative Group of the European Study Group on Nosocomial Infections. A European perspective on nosocomialurinary tract infections II. Report on incidence, clinical characteristics and outcome (ESGNI004study). European Study Group on Nosocomial Infection. Clin Microbiol Infect. 2001Oct;7(10):532-42.

5. Dellinger RP, Levy MM, Rhodes A, Annane D, Gerlach H, Opal SM, Sevransky JE, Sprung CL, Douglas IS, Jaeschke R, Osborn TM, Nunnally ME, Townsend SR, Reinhart K, Kleinpell RM, Angus DC, Deutschman CS, Machado FR, Rubenfeld GD, Webb SA, Beale RJ, Vincent JL, Moreno R; Surviving Sepsis Campaign Guidelines Committee including the Pediatric Subgroup. Surviving sepsis campaign: international guidelines for management of severe sepsis and septic shock: 2012. Crit Care Med. 2013 Feb; 41 (2):580-637.doi:10.1097/CCM.0b013e31827e83af.

6. Concia E, Azzini A M. Aetiology and Antibiotic Resistance Issues Regarding Urological Procedures. J Chemother. 2014;26 Suppl 1:S14-23.

7. Bellomo R, Morimatsu H, Morgera S, Schetz M, et al. Continuous Renal Replacement Therapy: A World wide Practice Survey, The Beginning and ending supportive therapy for the kidney (B.E.S.T. Kidney) Investigators. Intensive Care Med 2007;33:1563-70. 


\section{Case Report}

8. Naber KG, Bergman B, Bishop MC, BjerklundJohansen TE, Botto H, Lobel B, Jinenez Cruz F, Selvaggi FP; Urinary Tract Infection (UTI) Working Group of the Health Care Office (HCO) of the European Association of Urology (EAU). EA
Uguidelines for the management of urinary and male genital tractinfections. Urinary Tract Infection (UTI) Working Group of the Health Care Office (HCO) of the European Association of Urology (EAU). Eur Urol. 2001 Nov;40(5):576-88.

\section{How to cite this article?}

Prabowo S, Dita A. Early CRRT and antibiotic management in shock patient due to urosepsis with immunocompromised post renal transplantation. Int J Med Res Rev 2018;6 (04):204-209. doi:10.17511/ijmrr. 2018.i04.01. 